The University of Maine

DigitalCommons@UMaine

Finance Faculty Scholarship

Finance

1999

\title{
The Effects of Blending Primary and Diluted EPS Data
}

Ralph Goldsticker

Pankaj Agrrawal

University of Maine - Main, pankaj.agrrawal@maine.edu

Follow this and additional works at: https://digitalcommons.library.umaine.edu/finance_facpub

Part of the Accounting Commons, Finance and Financial Management Commons, and the Portfolio and Security Analysis Commons

\section{Repository Citation}

Goldsticker, Ralph and Agrrawal, Pankaj, "The Effects of Blending Primary and Diluted EPS Data" (1999). Finance Faculty Scholarship. 3.

https://digitalcommons.library.umaine.edu/finance_facpub/3

This Article is brought to you for free and open access by DigitalCommons@UMaine. It has been accepted for inclusion in Finance Faculty Scholarship by an authorized administrator of DigitalCommons@UMaine. For more information, please contact um.library.technical.services@maine.edu. 


\title{
The Effects of Blending Primary and Diluted EPS Data
}

\author{
Ralph P. Goldsticker and Pankaj Agrrawal
}

\begin{abstract}
Companies are now reporting basic and diluted, rather than primary and fully diluted, earnings per share. And a number of vendors changed from providing only primary EPS to providing only diluted EPS. They are also providing growth rates calculated from a blend of primary and diluted EPS. The growth rates calculated from a blended earnings stream will be lower than growth rates calculated from only primary or only diluted earnings, and the more years that are blended, the greater the reduction in the growth rate. The average differences in growth rates calculated from the various combinations of primary and diluted earnings are not large enough to be a cause for concern, but at the company level, blending earnings can produce growth rates that are substantially different from those produced when only primary or only diluted EPS are used.
\end{abstract}

$S$ tarting with reporting periods ending after December 15, 1997, companies began reporting basic and diluted earnings per share rather than primary and fully diluted earnings per share. ${ }^{1}$ Although companies are reporting the two types of EPS, a number of vendors that collect such information and provide it to the investment community (such as I/B/E/S International, First Call, and Interactive Data Corporation) are collecting and reporting only diluted EPS data. Previously, they provided only primary EPS data. This practice is consistent with findings by Jennings, LeClere, and Thompson (1997) that "fully diluted EPS explains more price variation than primary EPS" and "analysts and investors do not ignore potential dilution when pricing shares" (p. 31). As a consequence, the historical EPS growth rates that the vendors provide may be calculated by using an earnings stream that is a blend of primary EPS (for periods before mid-December 1997) and diluted EPS (for later periods). This heterogeneous composition of historical time-series EPS data may affect the EPS growth rates calculated and reported by the vendors, which has consequences for the investment industry that have not been fully explored.

We discuss the impact of blending diluted EPS with primary EPS in the calculation of historical

Ralph P. Goldsticker, CFA, is director of research at $\mathrm{Mel}$ lon Capital Management Corporation. Pankaj Agrrawal is vice president of Quantitative Equities at Putnam Investments.
EPS growth rates, and we evaluate the impact of dilution on the EPS data now being reported. We studied the nature and magnitude of these effects by examining individual companies and the aggregation of the data into 15 economic sectors.

We also present a comparison of primary and diluted EPS in general. The objective is to provide insight into the impact of the change in reporting standards and in the earnings data reported by vendors.

\section{Data and Methodology}

The sample of stocks for the study began with the 3,000 stocks that were included in the Russell 3000 Index as of January 30, 1998. The primary and diluted EPS were obtained from the Compustat annual files. Price, capitalization, and economic sector classification data are from the proprietary databases of Vestek Systems, which uses other vendors for data on price and shares outstanding.

Growth rates were calculated by using a formula used by $\mathrm{I} / \mathrm{B} / \mathrm{E} / \mathrm{S}$ for calculating historical earnings per share growth (HEPSG), which is defined as average annualized EPS growth for a company over five years. HEPSG is calculated by measuring the slope of a least squares curve fit to the (natural) logarithm of the reported earnings (a log-linear curve). It is expressed as a percentage. If only annual observations are available, I/B/E/S fits the curve to the last six annual observations (five time periods) and uses the exponentiated slope to represent the growth factor. Zero and 
negative observations are excluded from the calculations (I/B/E/S Glossary of Terms 1998).

This description can easily be recast into the following forms:

$$
E P S_{t}=(1+g)^{t} E P S_{0}
$$

and

$$
\ln \left(E P S_{t}\right)=\ln \left(E P S_{0}\right)+t \ln (1+g),
$$

where $E P S_{t}$ is earnings per share for time period $t$ and $t$ is $0,1,2,3,4,5$.

Using the last six years of EPS values, the coefficient of the estimate was expressed as

$$
\beta=\ln (1+g) \text {. }
$$

Then, we estimated the growth as

$$
g=\exp (\beta)-1
$$

This value of $g$ is the HEPSG. We calculated growth rates using the following four combinations of primary (subscript $P$ ) and/or diluted (subscript $D$ ) EPS:

- HEPSG $:$ 1991-96 EPS (six years of primary EPS),

- HEPSG $_{B 1}$ : 1991-95 EPS , and 1996 EPS $_{D}$ (five years of primary and one year of diluted EPS, where $B$ indicates blending),

- HEPSG $_{B 2}$ : 1991-94 EPS and 1995-96 EPS (four years of primary and two years of diluted EPS), and

- HEPSG $_{D}$ : 1991-96 EPS (six years of diluted EPS). ${ }^{2}$

Of the 3,000 companies in the index as of January 30, 1998, earnings were not available for
1,021 companies for the year $1991 .^{3}$ Furthermore, on average, about 360 companies had either negative or zero EPS each year from 1991 through 1996. ${ }^{4}$ After incorporating these two conditions, we had a final set of 1,127 companies with usable EPS for all six years.

\section{Blending and Dilution in Aggregate and by Sector}

We present results for the entire universe and results by economic sector.

Average Growth Rates. The summary (equalweighted average) growth rates based on the four sets of 1,127 regressions are reported in Table 1 . The table also shows the average differences between growth rates calculated using six years of primary EPS and the other combinations. The first row reports that for the 1,127-company universe, the average six-year $H_{E P S G}$ is 6.72 percent and the average six-year $H E P S G_{D}$ is 6.70 percent. Thus, whether $E P S_{P}$ or $E P S_{D}$ is used has little impact on the average growth rate. A difference does emerge, however, when the grow th rates calculated by using blended streams of EPS are examined. The average HEPSG $G_{p}$ is 0.10 percentage points (pps) larger than $H E P S G_{B 1}$ and 0.16 pps larger than $H_{E P S G}$.

Table 1 also reveals little variation among the four growth rates within each economic sector but

\begin{tabular}{|c|c|c|c|c|c|c|c|c|}
\hline \multirow[b]{2}{*}{ Sector } & \multirow[b]{2}{*}{$\begin{array}{l}\text { Number of } \\
\text { Companies }\end{array}$} & \multicolumn{4}{|c|}{ Five-Year Earnings Growth } & \multicolumn{3}{|c|}{$\begin{array}{c}\text { Difference in Growth Rates } \\
\text { (primary minus blended or diluted) }\end{array}$} \\
\hline & & HEPSG $_{\mathrm{P}}$ & $H_{E P S G}$ & HEPSG $_{B 2}$ & $H_{E P S G}$ & HEPSG $_{\mathrm{B} 1}$ & $\mathrm{HEPSG}_{\mathrm{B} 2}$ & $H_{E P S G_{D}}$ \\
\hline Universe & 1,127 & $6.72 \%$ & $6.62 \%$ & $6.56 \%$ & $6.70 \%$ & $0.10 \mathrm{pps}$ & $0.16 \mathrm{pps}$ & $0.02 \mathrm{pps}$ \\
\hline Business equipment & 79 & 6.66 & 6.60 & 6.56 & 6.51 & 0.05 & 0.10 & 0.14 \\
\hline Capital goods & 88 & 13.57 & 13.46 & 13.39 & 13.49 & 0.10 & 0.18 & 0.08 \\
\hline Consumer durables & 28 & 11.84 & 11.73 & 11.66 & 11.77 & 0.11 & 0.18 & 0.07 \\
\hline Consumer nondurables & 104 & 0.88 & 0.78 & 0.72 & 0.90 & 0.10 & 0.16 & -0.02 \\
\hline Consumer services & 45 & 5.28 & 5.23 & 5.18 & 5.41 & 0.06 & 0.10 & -0.12 \\
\hline Energy & 38 & 14.20 & 14.06 & 13.99 & 14.97 & 0.15 & 0.22 & -0.77 \\
\hline Finance & 204 & 5.46 & 5.30 & 5.21 & 5.54 & 0.15 & 0.25 & -0.08 \\
\hline Health care & 71 & 5.95 & 5.86 & 5.80 & 5.99 & 0.10 & 0.15 & -0.03 \\
\hline Multi-industry & 5 & 5.75 & 5.70 & 5.66 & 5.84 & 0.06 & 0.09 & -0.09 \\
\hline Raw material & 55 & 14.73 & 14.56 & 14.50 & 14.28 & 0.17 & 0.23 & 0.45 \\
\hline Retail & 79 & 2.46 & 2.36 & 2.27 & 2.45 & 0.10 & 0.18 & 0.00 \\
\hline Shelter & 61 & 10.30 & 10.22 & 10.19 & 10.27 & 0.08 & 0.11 & 0.03 \\
\hline Technology & 106 & 15.50 & 15.38 & 15.28 & 15.16 & 0.13 & 0.23 & 0.34 \\
\hline Transportation & 26 & 1.70 & 1.65 & 1.62 & 1.68 & 0.04 & 0.08 & 0.01 \\
\hline Utilities & 138 & -1.65 & -1.68 & -1.68 & -1.64 & 0.03 & 0.03 & -0.01 \\
\hline
\end{tabular}
considerable variation among the sectors. Average HEPSG $_{P}$ varies from a low of -1.65 percent (for

Table 1. Equal-Weighted Average Exponential Growth Rates Based on Four Sets of Earnings, 1991-96 
utilities) to a high of 15.50 percent (for technology). The sector average growth rates when the different earnings streams were used in the calculations are similar, and rankings based on them would be the same. Also, differences in the average growth rates for the sectors show the same pattern as for the entire universe $\left(H E P S G_{P}>H E P S G_{B 1}>H E P S G_{B 2}\right)$. At the same time, at the sector level, no systematic relationship was found between $H E P S G_{P}$ and $H E P S G_{D}$. Average HEPSG is less than the $H E P S G_{D}$ for 7 of the 15 economic sectors; $H E P S G_{p}$ is greater than the HEPSG ${ }_{D}$ for 7 of the sectors; and for 1 sector, the growth rates are the same.

HEPSG $G_{P}$ versus $H E P S G_{D}$ by Sector. The economic sectors' average grow th rates calculated by using primary EPS are plotted against the average difference between growth rates calculated by using primary EPS and by using diluted EPS in Figure 1. Each point on the plot represents the equal-weighted average of the stocks in that economic sector. The difference in growth rates is largest for the raw material and the technology sectors. Not only do those sectors have the highest HEPSG $_{p}$, (more than 14 percent), but also the average growth rates calculated for them by using primary EPS are more than 0.30 pps greater than the growth rates calculated by using diluted EPS. This difference is considerably higher than the universe average of $0.02 \mathrm{pps}$. The energy, consumer services, finance, and multi-industry sectors have lower grow th rates when primary EPS is used than when diluted EPS is used. The utility sector is the only sector for which the average growth rate of primary EPS is negative.

The findings for the energy sector are very different from the findings for the other sectors for an interesting reason. In the energy sector, the average $H E P S G_{D}$ exceeds the average $H E P S G_{p}$ by more than $0.75 \mathrm{pps}$, and the primary driver is one stock - Key Energy Group. As discussed later, a 60 percent antidilutive effect in EPS in 1991 caused this company's HEPSG ${ }_{D}$ to exceed HEPSG, by more than 34 pps. Exclusion of Key Energy would have resulted in an average difference in growth rates for the energy sector of $-0.1479 \mathrm{pps}$, which would have placed it in line with the other sectors.

The dramatic change in the energy sector average is an illustration of the importance of looking at stock-level detail. Portfolio managers who formed their views about the likely earnings growth of energy stocks based on aggregate values

Figure 1. Earnings Growth Rate versus Change in Growth with No Blending: $H_{E P S G_{p}}$ versus HEPSG $_{P}$ minus HEPSG, $1991-96$ Data

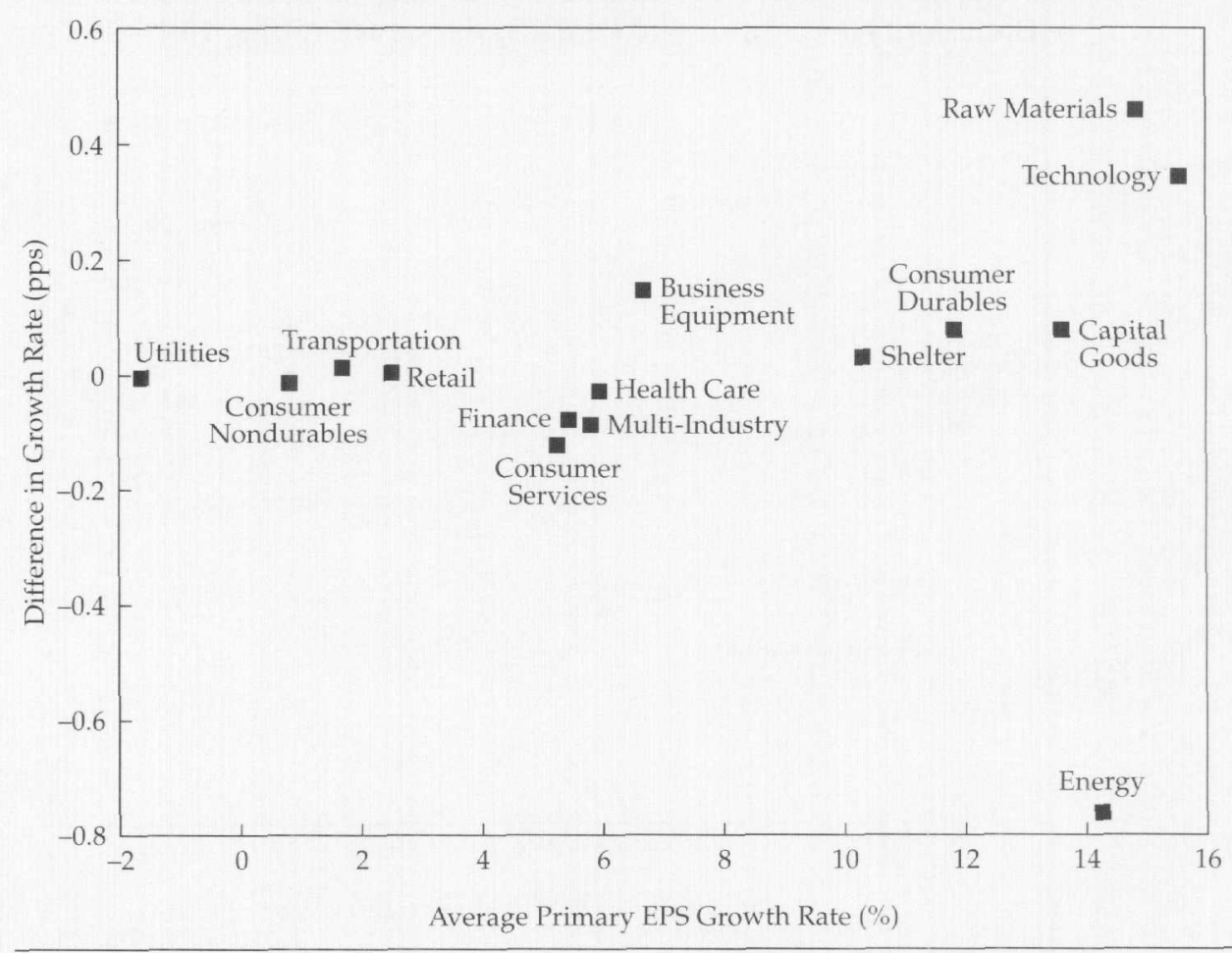


would have different opinions from those who understood the true picture through their analysis of company-level data.

The EPS numbers for Key Energy are correct, so the aggregate finding cannot be dismissed as a result of bad data. However, as our analysis shows, including the "good" data may not always be appropriate or desirable when calculating aggregate statistics.

HEPSG $_{P}$ versus $H E P S G_{B 1}$ by Sector. In the same manner as Figure 1, Figure 2 shows the impact on the economic sectors of blending one year of diluted EPS with five years of primary EPS, The location of the sectors on the vertical axis is different from Figure 1 because the impact on growth rates of blending primary and diluted EPS is different from the impact of comparing growth rates calculated by using primary versus diluted earnings. For example, the finance sector goes from having an average difference between ${ } E P S G_{p}$ and $H E P S G_{D}$ to having an above-average difference between $H_{E P S G}$ and $H_{E P S G_{B 1}}$.

\section{Importance of Company-Level Analysis}

Table 2 provides statistics on the earnings growth for $H_{E P S G}$ and differences in growth rates between $H E P S G_{p}$ and $H E P S G_{B 1}$ by universe and by sector. The rates were calculated by using the same data as used for Table 1 . Note that the HEPSG growth rates of the 1,127 companies have (approximately) a cross-sectional standard deviation of 22 percent, a minimum of -59 percent, and a maximum of +160 percent. Considerable variation also appears in the growth rates of primary EPS for each economic sector. The changes in growth rates between those calculated using primary EPS and those calculated with a blended earnings stream also show significant variation by sector. The maximum reduction in growth rate by blending is more than 2.5 pps. (The minimum reduction brought about by blending is not shown because it is zero.) The sizable variation in growth rates and variation in the change in growth rates underline the need, despite the small change in average growth rates, for stock-by-stock scrutiny of the impact of blending EPS on calculated growth rates.

Two scatter plots illustrate the importance of examining stock-level data. The graphic images show the general distribution of the data and have the added benefit of not obfuscating the isolated but interesting cases.

Figure 3 plots $H E P S G_{P}$, against the difference between $H_{E P S G_{P}}$, and HEPSG $_{B 1}$ by company.

The stocks fit one of the following cases:

- Most of the stocks have HEPSG between -20.0

Figure 2. Primary Earnings Growth Rate versus Change in Growth with Impact of Blending: HEPSG $_{P}$ versus HEPSG minus HEPSG $_{B 1}, 1991-96$ Data

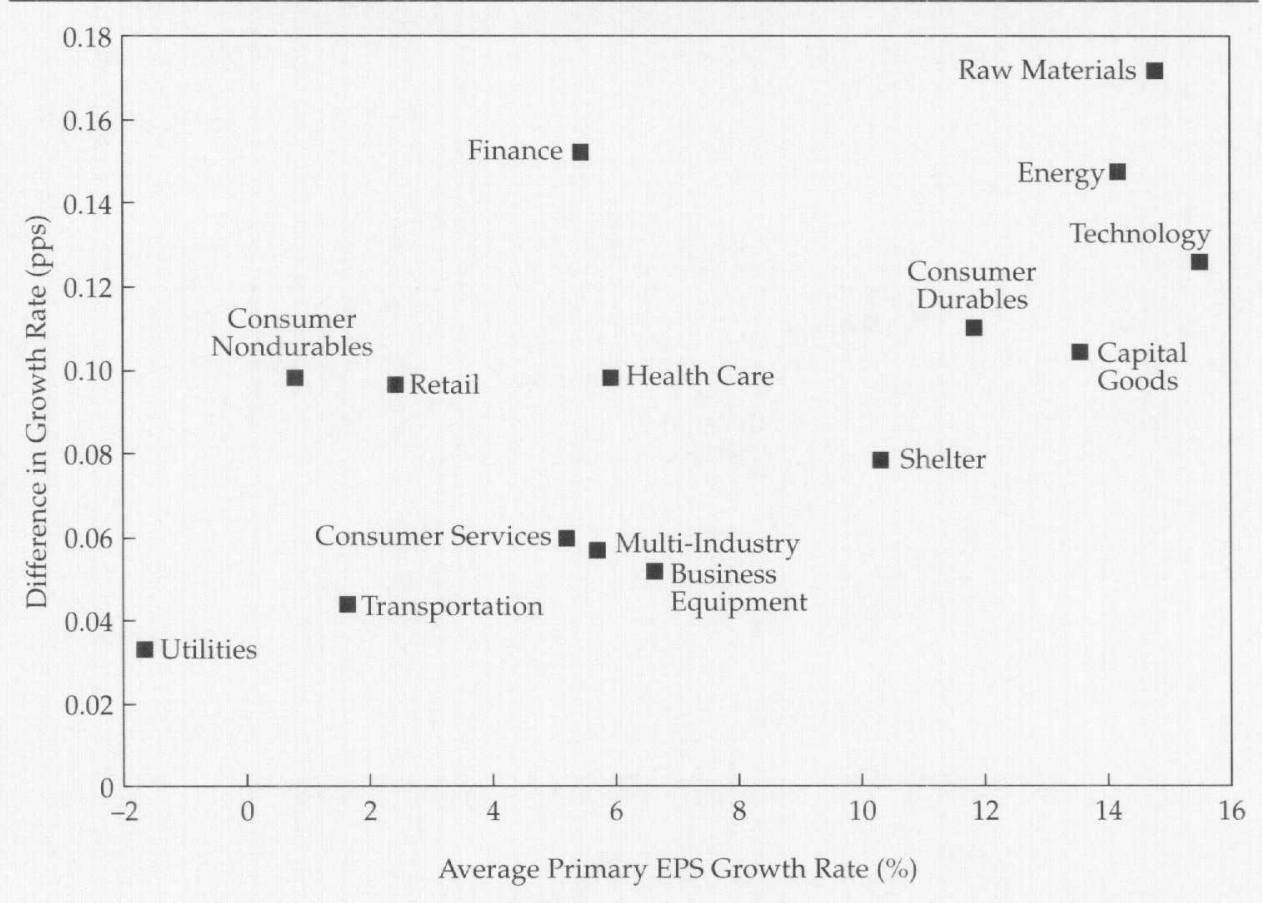


Table 2. Statistical Data on Growth Rates: $H_{E P S G_{P}}$ and the Difference between $H E P S G_{P}$ and HEPSG $_{B 1}, 1991-96$

\begin{tabular}{|c|c|c|c|c|c|c|c|}
\hline \multirow[b]{2}{*}{ Sector } & \multicolumn{4}{|c|}{$\begin{array}{l}\text { Five-Year Exponential Earnings Growth } \\
\qquad\left(H_{\left.P S G_{P}\right)}\right.\end{array}$} & \multicolumn{3}{|c|}{$\begin{array}{l}\text { Difference in Growth Rates } \\
\left({ }^{\text {HPSG }} \text { minus }_{P} \text { HPSG }_{B 1}\right)\end{array}$} \\
\hline & Mean & $\begin{array}{l}\text { Standard } \\
\text { Deviation }\end{array}$ & Minimum & Maximum & Average & $\begin{array}{l}\text { Standard } \\
\text { Deviation }\end{array}$ & Maximum \\
\hline Universe & $6.72 \%$ & $22.03 \%$ & $-59.39 \%$ & $160.82 \%$ & 0.10 pps & $0.28 \mathrm{pps}$ & $2.57 \mathrm{pps}$ \\
\hline Business equipment & 6.66 & 23.84 & -32.42 & 112.77 & 0.05 & 0.11 & 0.47 \\
\hline Capital goods & 13.57 & 26.46 & -20.04 & 135.41 & 0.10 & 0.25 & 1.33 \\
\hline Consumer durables & 11.84 & 23.83 & -12.15 & 111.73 & 0.11 & 0.42 & 2.27 \\
\hline Consumer nondurables & 0.88 & 19.28 & -39.84 & 112.56 & 0.10 & 0.24 & 1.28 \\
\hline Consumer services & 5.28 & 23.65 & -59.39 & 75.97 & 0.06 & 0.23 & 1.48 \\
\hline Energy & 14.20 & 22.80 & -18.52 & 73.59 & 0.15 & 0.43 & 2.57 \\
\hline Finance & 5.46 & 19.78 & -37.88 & 160.82 & 0.15 & 0.37 & 2.45 \\
\hline Health care & 5.95 & 20.11 & -31.09 & 85.53 & 0.10 & 0.25 & 1.73 \\
\hline Multi-industry & 5.75 & 8.74 & -11.47 & 11.72 & 0.06 & 0.11 & 0.28 \\
\hline Raw material & 14.73 & 30.49 & -40.34 & 135.82 & 0.17 & 0.37 & 1.83 \\
\hline Retail & 2.46 & 14.13 & -39.93 & 39.74 & 0.10 & 0.22 & 1.44 \\
\hline Shelter & 10.30 & 19.01 & -25.13 & 58.94 & 0.08 & 0.25 & 1.47 \\
\hline Technology & 15.50 & 26.66 & -26.72 & 134.48 & 0.13 & 0.31 & 1.69 \\
\hline Transportation & 1.70 & 17.97 & -51.46 & 46.01 & 0.04 & 0.16 & 0.72 \\
\hline Utilities & -1.65 & 13.22 & -52.57 & 85.98 & 0.03 & 0.13 & 1.05 \\
\hline
\end{tabular}

percent and +30.0 percent, and the impact of incorporating one year of $E P S_{D}$ reduced the historical EPS growth by less than 0.5 pps.

- Many of the stocks with growth rates in excess of 25.0 percent also reveal a change in historical EPS growth rates from blending one year of diluted EPS with five years of primary EPS of less than 0.5 pps.

- For a substantial number of stocks, the decline in historical EPS growth from blending one year of diluted EPS is larger than 0.5 pps. If most of these cases are associated with stocks

Figure 3. Impact of Blending on EPS Growth Rate by Company: HEPSGP versus HEPSG $_{P}$ minus HEPSG ${ }_{B 1}, 1991-96$ Data

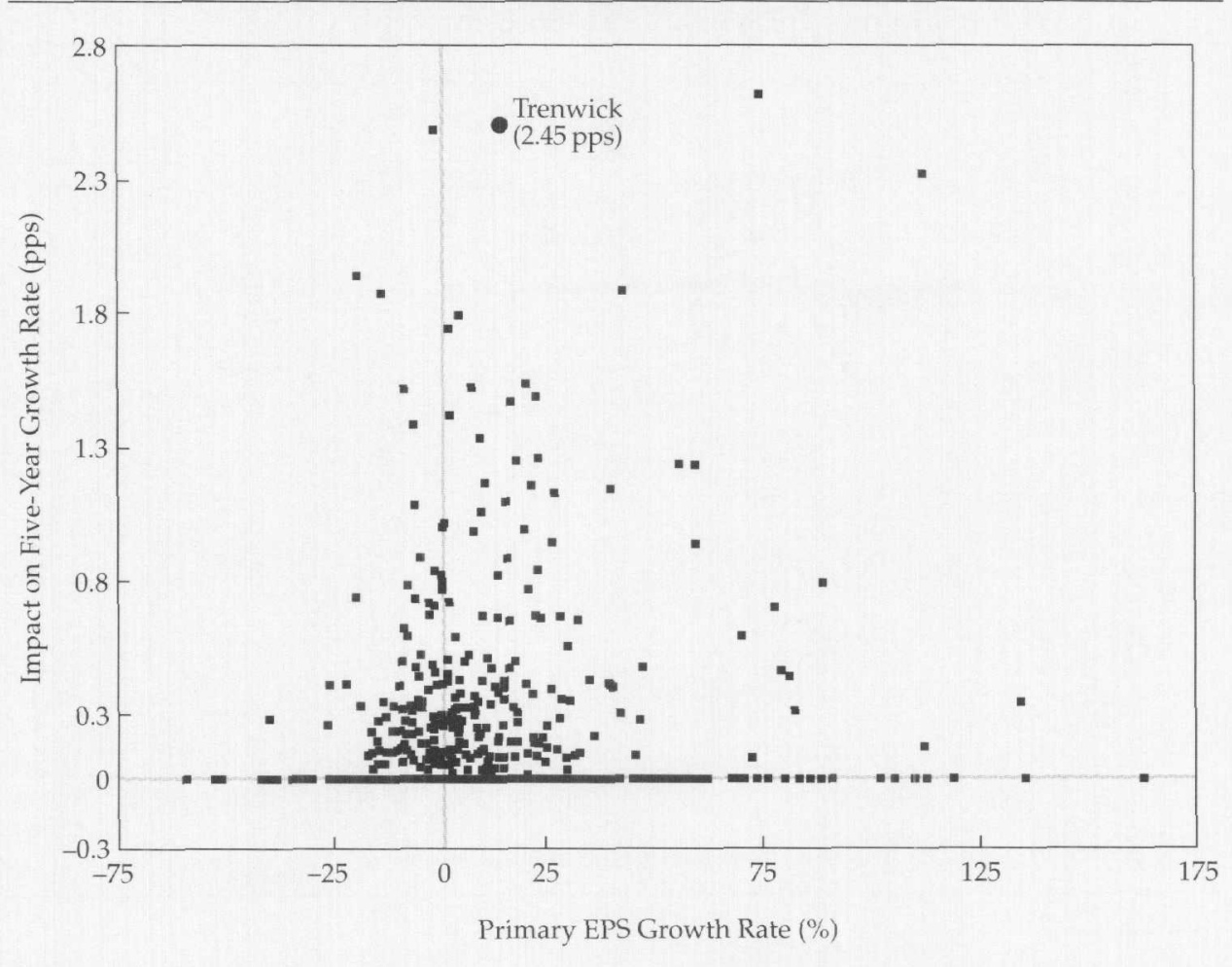

March/April 1999 
with very high historical EPS growth rates, they are not of much concern. The scatter plot clearly shows, however, that a number of these stocks have relatively low growth rates and relatively substantial drops in $H E P S G_{B 1}$. A 1.5 pp decline in the growth rate on a stock with a 10 percent historical EPS growth rate should be interpreted as considerable. Clearly, this change is simply a result of blending $E P S_{D}$ and $E P S_{p}$ in calculating historical EPS growth and does not convey any new economic information about the company.

Impact of Blending. For some companies, the impact on historical EPS growth of blending diluted with primary earnings is dramatic. The case of Trenwick Group is a good example. Table 3 provides 1991-96 primary EPS and diluted EPS for Trenwick. The data produce a six-year HEPSG of 13.53 percent and a six-year $H E P S G_{B 1}$ of 11.09 percent. The 14 percent difference between Trenwick's 1996 primary EPS and diluted EPS (\$4.25 versus $\$ 4.95$ ) resulted in the $H E P S G_{B 1}$ being less than the $H E P S G_{p}$ by 2.45 pps. By any measure, this amount is a significant portion of the company's HEPSG $_{p}$ of 13.53 percent. This point ( +2.45 pps) is highlighted on Figure 3.

Impact of Dilution. The importance of company-level analysis is also evident when analyzing the difference caused by using primary EPS versus using diluted EPS to calculate grow th rates. Figure 4 shows the distribution of the differences in growth rates calculated by using all primary EPS

Table 3. Examples: Trenwick Group, Key Energy Group, and Ducomunn, 1991-96

\begin{tabular}{|c|c|c|c|c|c|c|}
\hline \multirow[b]{2}{*}{ Year } & \multicolumn{2}{|c|}{ Trenwick } & \multicolumn{2}{|c|}{ Key Energy } & \multicolumn{2}{|c|}{ Ducomunn } \\
\hline & $\begin{array}{c}\text { Primary } \\
\text { EPS }\end{array}$ & $\begin{array}{l}\text { Diluted } \\
\text { EPS }\end{array}$ & $\begin{array}{c}\text { Primary } \\
\text { EPS }\end{array}$ & $\begin{array}{l}\text { Diluted } \\
\text { EPS }\end{array}$ & $\begin{array}{c}\text { Primary } \\
\text { EPS }\end{array}$ & $\begin{array}{c}\text { Diluted } \\
\text { EPS }\end{array}$ \\
\hline 91 & $\$ 2.79$ & $\$ 2.79$ & $\$ 0.05$ & $\$ 0.02$ & $\$ 0.72$ & $\$ 0.72$ \\
\hline 92 & 2.51 & 2.50 & 0.02 & 0.01 & 0.61 & 0.66 \\
\hline 93 & 3.48 & 3.12 & 0.63 & 0.63 & 0.49 & 0.48 \\
\hline 94 & 3.04 & 2.78 & 0.22 & 0.25 & 0.48 & 0.48 \\
\hline 95 & 4.44 & 3.80 & 0.33 & 0.33 & 1.04 & 0.87 \\
\hline 96 & 4.95 & 4.25 & 0.44 & 0.44 & 1.45 & 1.33 \\
\hline
\end{tabular}

Figure 4. Difference in Earnings Growth Rates by Company: $H E P S G_{p}$ versus HEPSG $_{P}$ minus HEPSG ${ }_{D}, 1991-96$ Data

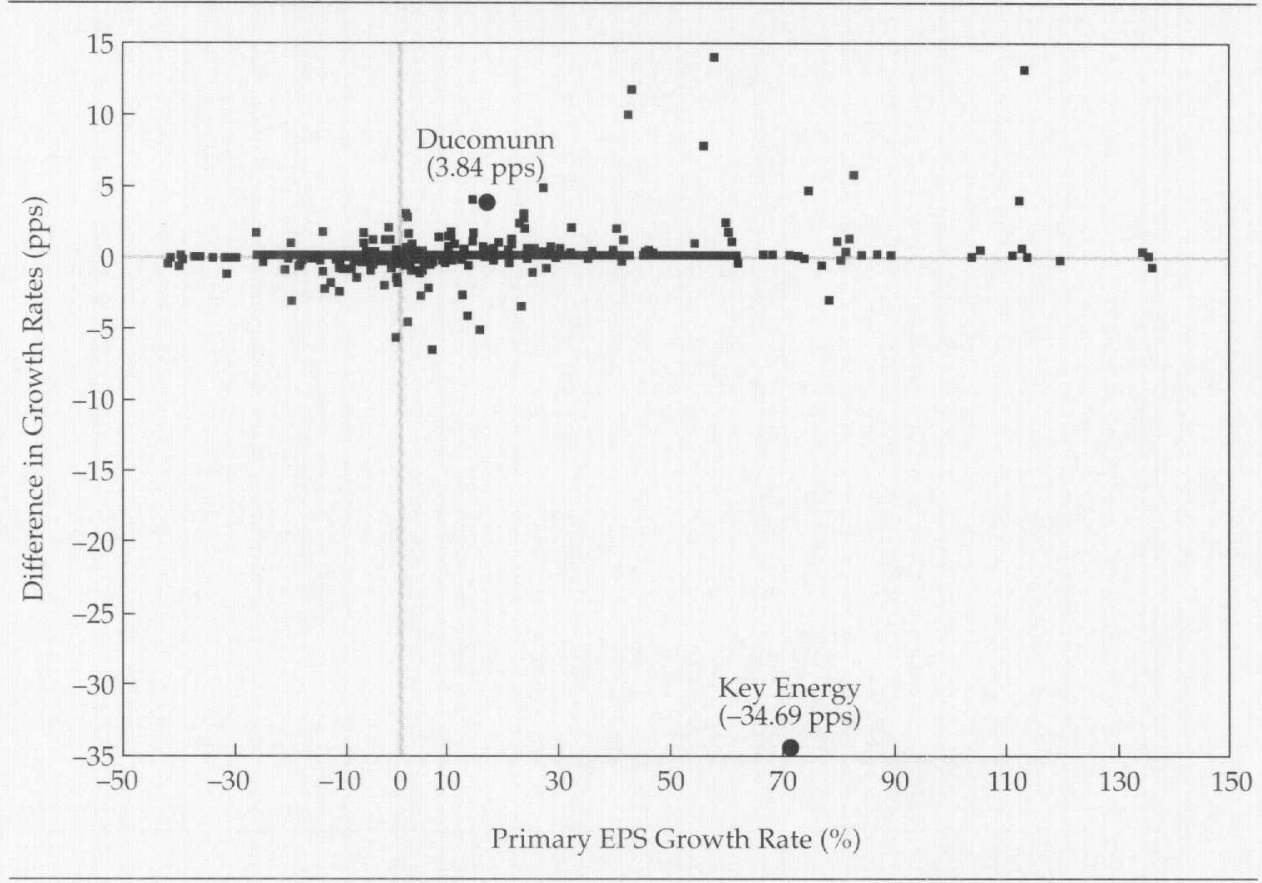


and using all diluted EPS. The stocks with positive EPS growth rates based on primary EPS and for which $H E P S G_{P}$, exceeds $H E P S G_{D}$ are in the upper right quadrant. The stocks with positive growth rates based on primary EPS and for which ${ } E P S G_{P}$ is lower than the $H E P S G_{D}$ are in the lower right quadrant. For most of the stocks, the difference in growth rates is relatively small, but the growth rates are significantly different for a large minority of stocks. Note the following:

- As one would expect when the amount of dilutive securities is increasing in a period, we found more stocks for which the growth rate calculated using primary EPS was higher than the growth rate calculated using diluted EPS.

- For stocks with negative earnings growth rates, we found the difference in growth rates based on primary versus diluted earnings always to be relatively small.

- For many of the fastest-growing stocks, the growth rates calculated by using primary and diluted earnings were the same. The implication is that amount of dilution was relatively stable for these companies in the study period. This suggestion is contrary to the conventional wisdom that high-growth companies have been increasing dilution through employee stock option plans.

Key Energy Group is an example of a company with a significant difference between growth rates calculated by using primary earnings and using diluted earnings. Indeed, Key Energy illustrates the distortions that the change in calculating EPS caused in the average growth rate for the energy sector. As Table 3 shows, the only significant difference between primary EPS and diluted EPS occurred in 1991, but the reduction of three cents a share resulted in what would have been an $H E P S G_{P}$ of about 69 percent rising to an $H E P S G_{D}$ of about 104 percent. The difference $(-34.69 \mathrm{pps})$ is noted on Figure 4.

The case of Key Energy is interesting and dramatic, but its economic significance is doubtful. In contrast, the case of Ducomunn is an example of a change that is dramatic and, if its cause were not understood, could be interpreted as an economically meaningful difference. Ducomunn's primary and diluted EPS for 1991 through 1996 are provided in Table 3. The results are an HEPSG $p$ of 15.62 percent and an $H_{E P S G_{D}}$ of 11.78 percent, a difference of $3.84 \mathrm{pps}$ (also noted in Figure 4). For a company like Ducomunn with a relatively average EPS growth rate, this reduction is significant, but as this discussion shows, Ducomunn experienced no change in earnings. The only change was the form of reported earnings used in the calculation of the growth rate.
Figures 3 and 4 show that for most stocks, the difference between earnings growth rates calculated by using primary earnings and those calculated by using diluted earnings is not meaningful. For some companies, however, HEPSG $p$ differs from $H E P S G_{D}$ by more than 5 pps. Also, for some companies, blending one year of diluted EPS into the calculation reduces the historical EPS growth rate by more than 1 pps. Thus, employee stock options, convertible securities, and other forms of dilution can have a pronounced effect on the calculation of historical EPS growth rates. Moreover, although aggregation may not show these differences, stock-level details do.

Some analysts have suggested that growth rates or differences in growth rates may be related to companies' market capitalizations. The scatter plot in Figure 5 clearly indicates that a relationship exists between market capitalization and the difference between HEPSG $_{p}$ and HEPSG $_{B 1}$. The largest differences between the growth rates occur among small-cap stocks. ${ }^{5}$

The importance of differences in EPS growth rates depends on how an analyst plans to use the numbers. Quantitative fund managers dealing with portfolios with large numbers of stocks have the benefit of diversification. To them, the blending of primary and diluted EPS may not be as important as it is to managers performing traditional security analysis. Analysts should be wary of changes in growth rates caused by a switch to blended earnings or to diluted earnings. Before extrapolating historical growth rates into the future, security analysts have to decide which growth rate is more predictive of the company's future growth.

\section{The Effects of Dilution}

An evaluation of the differences between diluted and primary EPS can throw light on the extent of dilution by economic sector. In our interaction with a wide range of clientele, we find that, although many are aware of the change in reporting requirements, some fuzziness about its likely effect remains.

This discussion addresses earnings for the entire sample and for economic sectors. Before extrapolating these results into the future, remember that the data used in this section are the data on primary and diluted earnings for 1996 only and are the data reported under the reporting requirements in effect at that time. The new Financial Accounting Standards Board rules for reporting basic and diluted earnings are different.

We chose to limit the analysis in this section to 1996, the most recent year for which complete data 


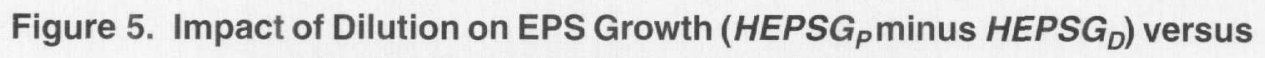

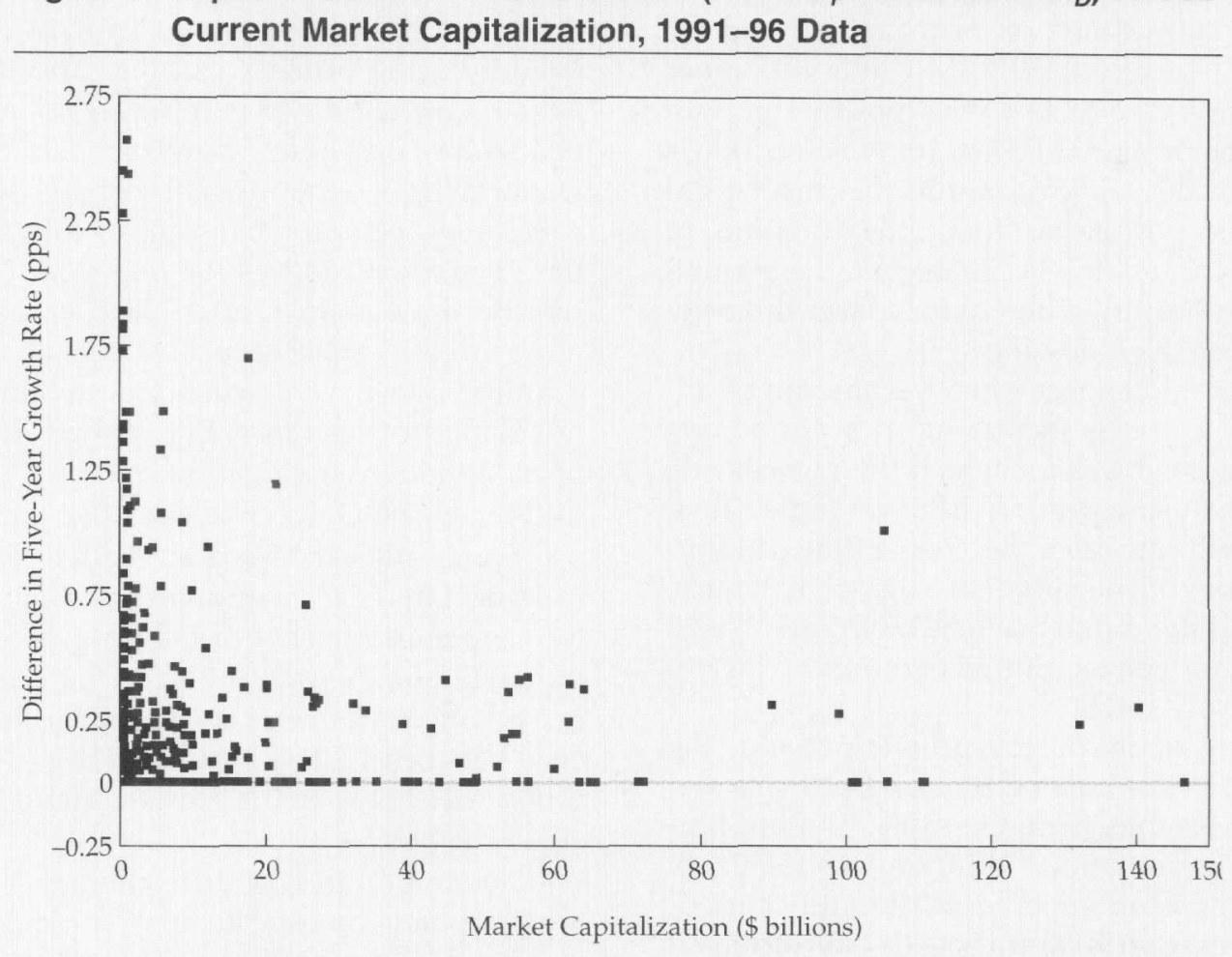

are available, in order to include the maximum number of companies and to minimize time-series averaging. The universe is again the Russell 3000 as of January 31, 1998. Of the 3,000 stocks in the index, only the 2,406 companies that had positive EPS for 1996 are included in this part of the analysis. $^{6}$

Table 4 reports the number of companies in each economic sector and the percentage of companies in that sector that were unaffected by dilution, had diluted EPS higher than primary EPS, and had diluted EPS lower than primary EPS. Table 4 also provides aggregate values for the universe.

The finance, raw material, and energy sectors had the most frequent occurrences of dilution. Companies in the consumer services, shelter, business equipment, and utilities sectors had the least frequent occurrences of dilution. Interestingly, 1.58 percent of the companies reported diluted EPS higher than primary EPS. More than 75 percent of the companies showed no impact from dilution.

Table 5 shows the extent of dilution (as opposed to occurrence of dilution) by economic sector and the sector mean and median values of the percentage decline in the diluted EPS relative to the primary EPS. These statistics were calculated from the subset of stocks that exhibited dilution; stocks with primary EPS equal to diluted EPS and stocks for which primary EPS was less than fully diluted EPS were excluded. Note that sectors with the highest incidence of dilution in earnings did not experience the greatest amount of dilution. Change in EPS was calculated two ways-once using EPS $P$ as the denominator and again using price as of December 31, 1996, as the denominator. We used price in the denominator to minimize the impact on the averages from stocks with very small earnings and nonmaterial but large percentage reductions in EPS from dilution. The decline in EPS using price as the denominator can also be interpreted as the decline in the earnings yield.

We show both mean and median values in Table 5 because the underlying distributions are not normally distributed. The means are driven by extreme values; the medians are more representative of the typical decline in EPS as a result of dilution. For the entire universe, the mean and median decline in EPS as a result of dilution when $E P S_{P}$ was the denominator were, respectively -2.88 percent and -1.70 percent. The mean and median impact of dilution when normalized by price were, respectively, -0.20 percent and -0.10 percent. This finding underlines the conclusion that the impact is not large in aggregate but that care must be used with stock selection.

Notice that the mean and median values for dilution in Table 5 are largest for the transportation sector. Although only 20 percent of the stocks in the transportation sector suffered from dilution (see 
Table 4. Impact of EPS Dilution: Russell 3000 Universe, Breakdown by Economic Sector, 1996

\begin{tabular}{|c|c|c|c|c|c|c|c|}
\hline \multirow[b]{2}{*}{ Sector } & \multicolumn{4}{|c|}{ Number of Companies per Sector } & \multicolumn{3}{|c|}{ Percentage per Sector } \\
\hline & $E P S_{D}=E P S_{P}$ & $E P S_{D}>E P S_{P}$ & $E P S_{D}<E P S_{P}$ & $E P S_{D} \& E P S_{P}>0$ & $\begin{array}{l}\text { Dilutive } \\
\text { Effect }\end{array}$ & No Effect & $\begin{array}{c}\text { Antidilutive } \\
\text { Effect }\end{array}$ \\
\hline Finance & 262 & 2 & 144 & 408 & $35 \%$ & $64 \%$ & $0 \%$ \\
\hline Multi-industry & 10 & 0 & 4 & 14 & 29 & 71 & 0 \\
\hline Raw material & 72 & 6 & 31 & 109 & 28 & 66 & 6 \\
\hline Energy & 75 & 4 & 30 & 109 & 28 & 69 & 4 \\
\hline Capital goods & 119 & 2 & 44 & 165 & 27 & 72 & 1 \\
\hline Health care & 123 & 3 & 36 & 162 & 22 & 76 & 2 \\
\hline Retail & 113 & 3 & 33 & 149 & 22 & 76 & 2 \\
\hline Technology & 230 & 3 & 66 & 299 & 22 & 77 & 1 \\
\hline Transportation & 41 & 2 & 11 & 54 & 20 & 76 & 4 \\
\hline \multicolumn{8}{|l|}{ Consumer } \\
\hline nondurables & 143 & 4 & 37 & 184 & 20 & 78 & 2 \\
\hline Consumer durables & 51 & 0 & 12 & 63 & 19 & 81 & 0 \\
\hline Utilities & 144 & 0 & 30 & 174 & 17 & 83 & 0 \\
\hline \multicolumn{8}{|l|}{ Business } \\
\hline equipment & 185 & 3 & 33 & 221 & 15 & 84 & 1 \\
\hline Shelter & 150 & 5 & 26 & 181 & 14 & 83 & 3 \\
\hline Consumer services & 98 & 1 & 15 & 114 & $\underline{13}$ & $\underline{86}$ & 1 \\
\hline Overall mean & & & & & $22.94 \%$ & $75.48 \%$ & $1.58 \%$ \\
\hline Overall total & 1,816 & 38 & 552 & 2,406 & & & \\
\hline
\end{tabular}

Note: Sorted by dilutive effect.

Table 5. Extent of EPS Dilution in Companies Exhibiting Dilution, 1996

\begin{tabular}{lccccc}
\hline & \multicolumn{2}{c}{ Mean } & & \multicolumn{2}{c}{ Median } \\
\cline { 2 - 3 } \cline { 5 - 6 } Sector & $\left(E P S_{D}-E P S_{P}\right) / E P S_{P}$ & $\left(E P S_{D}-E P S_{P}\right) /$ Price & & $\left(E P S_{D}-E P S_{P}\right) / E P S_{P}$ & $\left(E P S_{D}-E P S_{P}\right) / P$ Price \\
\hline Finance & $-2.63 \%$ & $-0.21 \%$ & $-1.19 \%$ & $-0.09 \%$ \\
Multi-industry & -2.77 & -0.16 & -1.55 & -0.06 \\
Raw material & -3.88 & -0.36 & -2.33 & -0.17 \\
Energy & -2.81 & -0.14 & -2.20 & -0.10 \\
Capital goods & -2.50 & -0.17 & -1.24 & -0.09 \\
Health care & -2.97 & -0.14 & -2.19 & -0.09 \\
Retail & -2.14 & -0.14 & -1.72 & -0.08 \\
Technology & -2.78 & -0.15 & -1.56 & -0.06 \\
Transportation & -8.22 & -1.08 & -4.97 & -0.56 \\
Consumer nondurables & -2.10 & -0.12 & -1.35 & -0.07 \\
Consumer durables & -3.30 & -0.33 & -1.79 & -0.08 \\
Utilities & -2.39 & -0.13 & -0.90 & -0.05 \\
Business equipment & -2.85 & -0.11 & -1.43 & -0.07 \\
Shelter & -4.23 & -0.25 & -2.04 & -0.15 \\
Consumer services & -2.56 & -0.14 & -2.13 & -0.07 \\
$\quad$ Average & $-2.88 \%$ & $-0.20 \%$ & $-1.70 \%$ & $-0.10 \%$ \\
\hline
\end{tabular}

Note: Sorted in same order as in Table 4.

Table 4), the stocks in that sector had the most dilution. Therefore, the reported EPS for transportation stocks are likely to be the most affected by the change in reporting requirements. Also note that, even though the stocks in the finance sector had the most frequent occurrences of dilution (see Table 3), on average, those stocks did not have a large amount of dilution. Thus, although the finance stocks are the most likely to be affected by the change in reporting, the impact of the change is likely to be small.

\section{Conclusion}

The primary objective of this article has been to enhance understanding of the implications of blending primary and diluted EPS in calculating historical EPS growth rates, a method that is being used by several suppliers of data to the investment industry. We focused in the first section on the impact of blending primary and diluted EPS in the calculation of historical five-year exponential growth rate in earnings. At the aggregate level, the 
impact of blending was barely discernible, but for the technology, energy, and raw material sectors, an effect was visible.

In the next section, we discussed the importance of examining the effects at the company level. Blending primary and diluted EPS has a significant effect for some companies. If analysts do not know the underlying figures, differences in growth rates that appear when blended EPS data are used in the calculations may appear to be economically meaningful when they are not. Therefore, we suggest caution in interpreting large swings in earnings growth rates when comparing growth rates calculated with different earnings streams.

We also reported on the incidence and magnitude of differences between primary and fully diluted EPS by sectors and showed that the impact of dilution varies by economic sector. Finally, we reported that the sectors with the highest incidence of dilution in EPS do not show the greatest amount of dilution in earnings. This finding underlines the necessity of investigating company details when using historical EPS growth rates to project future rates.

\section{Notes}

1. The change was required by Financial Accounting Statement No. 128, adopted in February 1997. Basic EPS excludes stock options, warrants, and convertible securities; it is less dilutive than primary EPS. The new "diluted" form is comparable to the old "fully diluted" form and reflects the dilution that stock options, warrants, and convertible securities may have on EPS. (An in-the-money warrant is an example of a dilutive security. The exercising of the warrant during the period would increase the total number of shares outstanding without a concomitant increase in earnings; therefore, EPS would decline.) Dilution rom large numbers of incentive stock options or other warrants, convertible securities, and other types of dilutive securities can eventually create a valuation problem.

2. The discussion focuses on the combinations of no blending and blending primary EPS with one year of diluted EPS.
The blending of two years of $E P S_{D}$, the third combination listed, showed results similar to those for the second combination, blending one year; the direction of the change was the same, and the magnitude of the change was greater. Thus, the interpretation of the results would be the same.

3. If a company had $E P S_{\Gamma}>0$ for year $t$ and $E P S_{D}$ for the same year was not available, we used the $E P S_{P}$ as $E P S_{D}$.

4. If a company had $E P S_{P} \leq 0$, the company was excluded in order to allow the logarithmic transformation and to have a regression based on five years of earnings growth.

5. Details of this analysis are available from the authors

6. We excluded stocks with missing, negative, or zero EPS because dilution is a meaningful concept only for stocks with positive earnings.

\section{References}

Barth, Mary E., Timothy B. Bell, Daniel W. Collins, and G. Michael. 1994. "Response to the FASB Prospectus 'Earnings per Share." Accounting Horizons, vol. 8, no. 2 (June): 111-113.

DeBerg, Curtis L., and Brock Murdoch. 1991. "The Immateriality of Primary EPS: What the Data Reveal." Financial Analysts Journal, vol. 47, no. 5 (September/October):91-95.

l/B/E/S Glusiany of Tomb. 1998. New York: I/B/E/S International.
Jennings, R., M.J. LeClere, and R.B. Thompson II. 1997. "Evidence on the Usefulness of Alternative Earnings per Share Measures." Financial Analysts Journal, vol. 53, no. 6 (November/ December):24-33.

Ng, Eng Juan. 1995. "Fully-Diluted Earnings per Share: The Issue of Anti-Dilution." Singmore Accotntant, vol. 11, no. 4 (July/August):26-31 